(C) Dr W. Junk Publishers, Dordrecht - Printed in the Netherlands

\title{
Ecological amplitudes of plant species and the internal consistency of Ellenberg's indicator values for moisture*
}

\author{
Cajo J. F. Ter Braak ${ }^{1}$ \& Niek J. M. Gremmen ${ }^{2 * *}$ \\ ${ }^{1}$ TNO Institute of Applied Computer Science, P.O. Box 100, $6700 \mathrm{AC}$ Wageningen, The Netherlands \\ ${ }^{2}$ Research Institute for Nature Management, P.O. Box 46, 3956 ZR Leersum, The Netherlands
}

Keywords: Amplitude, Gaussian logit curve, Indicator value, Logit regression, Maximum likelihood, Optimum, Tolerance, Unimodal response curve, Weighted averaging

\begin{abstract}
Two methods for estimating ecological amplitudes of species with respect to Ellenberg's moisture scale are discussed, one based on weighted averaging and the other on maximum likelihood. Both methods are applied to phytosociological data from the province of Noord-Brabant (The Netherlands), and estimate the range of occurrence of species to be about 4-6 units on the moisture scale. Due to the implicit nature of Ellenberg's definition of moisture, it is impossible to improve the indicator values in a statistically sound way on the basis of floristic data only. The internal consistency of the Ellenberg indicator values is checked by using Gaussian logit regression. For 45 out of the 240 species studied the indicator value is inconsistent with those of the other species. The same method is used to estimate the optima and amplitudes of species considered moisture-indifferent and of some species not mentioned by Ellenberg. Some of these 'indifferent' species show a remarkably narrow amplitude.
\end{abstract}

It is concluded that the Ellenberg indicator values for moisture form a reasonably consistent system.

\section{Introduction}

Ellenberg (1979) summarized the ecology of the Central-European vascular plants, by assigning to each species indicator values for light, temperature, moisture, nitrogen and acidity.

Ellenberg's indicator values are used to estimate the value of any of these environmental factors at a particular site by averaging the indicator values for this factor of all species present (e.g. Ellenberg, 1979, 1983; Persson, 1981; Smeets, Werger \& Tevonderen, 1980; Böcker, Kowarik \& Bornkamm, 1983). Plants often reflect temporally integrated environmental conditions and are therefore particularly useful indicators when values averaged over time are needed. When the value of an environmental factor in the past is required, the only possible approach may be to base it on historical vegetation data.

During the development of a model simulating the effects of withdrawal of groundwater on the disappearance of plant species (Gremmen et al., 1985; Reijnen \& Wiertz, 1984), we wished to know:

(1) do Ellenberg's indicator values for moisture and nitrogen correctly represent the optima of species for these factors in our study area,

(2) what is the ecological amplitude of each species for these factors, including species not mentioned by Ellenberg (1979)?

We will only discuss moisture values here. Clear-

\footnotetext{
* Nomenclature follows Heukels-Van der Meijden (1983), Flora van Nederland, 20th ed.

** We would like to thank M. J. S. M. Reijnen and J. Wiertz for the discussions that gave us the idea for this research. We are grateful to $\mathbf{J}$. de Bree, C. Hengeveld and the referees for comments on the manuscript. Part of this research was supported by the Commissie Grondwaterwet Waterleidingbedrijven, the Keuringsinstituut van Waterleidingartikelen, the Landinrichtingsdienst, Staatsbosbeheer, and the Ministerie van Volkshuisvesting, Ruimtelijke Ordening en Milieubeheer.
} 
ly, the same reasoning can be applied for other factors.

Ellenberg (1979) placed each species on a 12-point ordinal scale according to its distribution with respect to moisture (Table 1). It is not clear which characteristic(s) of the moisture regime (e.g. groundwater level, soil moisture content, and soil moisture deficit) were used in the definition of these classes. In practice the indicator values of Ellenberg's 'intuitive' scale seem to work well, however.

The implicit nature of Ellenberg's definition of moisture makes it impossible to check the correctness of the indicator values against actual measurements. Nevertheless, it is possible to check the internal consistency by comparing the indicator values of species that occur together: when a species mainly occurs together with species with higher (lower) indicator values, its indicator value is in comparison with those of the other species too low (too high). (When species have extreme indicator values this intuitive idea needs modification.) $\mathrm{Al}$ ternatively, the consistency of the Ellenberg moisture values could be checked by studying the distribution of each species with respect to moisture. In this approach the moisture value of a site is calculated by averaging the indicator values of the species present. The indicator value of a particular species is clearly inconsistent with those of the other species when it deviates considerably from the center of the distribution of this species. This distribution also contains information on the ecological amplitude of the species for moisture.

In this paper this simple method is developed

Table 1. Definition of Ellenberg's moisture values (Ellenberg, 1979).

1 on extremely dry soils, e.g. bare rocks

2 in-between 1 and 3

3 on dry soils

4 in-between 3 and 5

5 on fresh soils, i.e. under intermediate conditions

6 in-between 5 and 7

7 on moist soils which do not dry out

8 in-between 7 and 9

9 on wet, often not well aerated soils

10 on frequently inundated soils

11 water plant with leaves mostly in contact with the open air

12 underwater plant, mostly totally immersed in water

$x$ indifferent further and compared with a more sophisticated maximum likelihood method, in which the species' distributions are modelled by Gaussian logit curves (Ter Braak \& Looman, 1986). Both methods are applied to phytosociological (presence/absence) data from a diluvial part of The Netherlands to answer the questions stated above, the first of which being reformulated as: 'are Ellenberg's indicator values internally consistent in our study area?'.

\section{Methods}

\section{Type of response curve}

The relationship between the occurrence of a species and moisture may be shown in a presence-absence response curve, in which the probability $p(x)$ of occurrence of the species is plotted against moisture $(x)$. Response curves may differ in shape and vary in complexity, but the response curves of species with respect to environmental variables are usually unimodal (Ellenberg, 1983; Whittaker, 1956). In this study we assume a unimodal response curve for each species with respect to moisture. In such curves, the width of the curve is proportional to the ecological amplitude and the position of its maximum is the indicator value. These two concepts lose their meaning in other response curves, such as bimodal or sigmoid curves.

\section{Weighted averaging method}

In the method of weighted averaging the indicator value and ecological amplitude of a species are defined as the mean $(M)$ and standard deviation $(S D)$ of the species' response curve. Thus, these characteristics are defined as if a response curve $p(x)$ were a statistical probability distribution (see Ter Braak \& Barendregt, 1986). The moisture value of a relevé is estimated here as the average of Ellenberg's indicator values for moisture of all the species present in the relevé. Simplistic estimates of a species' indicator value and ecological amplitude would then be the sample mean and the sample standard deviation, respectively, of the moisture values of all relevés containing the species (Ter Braak \& Looman, 1986). The newly calculated indicator values might then be compared with the indicator values given by Ellenberg (1979) to provide an informal test on the internal consistency of the latter. However, these estimates are too simple, because they neglect the distribution of the moisture values and their results may be misleading (Ter Braak \& Looman, 1986). In an attempt to correct for the distribution of the moisture values, the moisture scale is divided into twelve classes, and the number of relevés, $n_{j}$, in each class $j$ is counted. For any species a rough estimate of its response curve can then be obtained by calculating the fraction of relevés in each class that contain the species. These fractions can be displayed in a response histogram (Fig. 1). Improved estimates for the indicator value and ecological amplitude are then the mean and standard deviation of the response histogram. In this study the ecological amplitude is estimated in a slightly more subtle way, namely by 


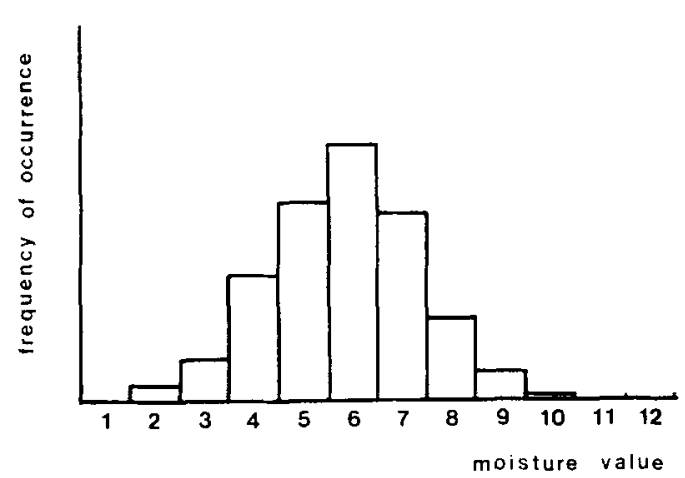

Fig. 1. Response histogram of a species with respect to moisture. The bars show the fraction of relevés in each moisture class which contain the species.

using Ellenberg's indicator value of the species instead of the sample mean in the formula for the standard deviation:

$$
\widetilde{S D^{2}}=\sum_{i=1}^{n} \frac{y_{i}}{n_{j}}\left(\tilde{x}_{i}-M_{o}\right)^{2} / \sum_{i=1}^{n} \frac{y_{i}}{n_{j}}
$$

where $n$ is the number of relevés, $y_{i}=1$ or 0 depending on whether the species is present or absent in releve $i$, $\tilde{x}_{i}$ is the estimated moisture value and $j$ the class of releve $i, n_{j}$ is the number of relevés in class $j$ and $M_{o}$ is Ellenberg's (1979) indicator value of the species. The latter is used in equation (1), instead of any newly computed indicator value, to avoid underestimation of the ecological amplitude. We also used some variants of equation (1), but the differences in the results did not seem to be of practical importance.

\section{Maximum likelihood method}

Ter Braak \& Looman (1986) proposed to model the presenceabsence response curve of a species by the Gaussian logit curve, in which the logit-transform of probability is a quadratic function. According to this model the probability $p_{i k}$ that species $k$ occurs in relevé $i$ is (Fig. 2)

$$
p_{i k}=1 /\left\{1+c_{k} \exp \left[1 / 2\left(x_{i}-u_{k}\right)^{2} / t_{k}^{2}\right]\right\}
$$

where $u_{k}$ is the optimum (the value of $x$ with highest probability of occurrence of species $k$ ) and $t_{k}$ is the tolerance (a measure of ecological amplitude) of species $k$ and $x_{i}$ is the moisture value of relevé $i$. The maximum probability of occurrence of species $k$ is $1 /\left(1+c_{k}\right)$. The Gaussian logit curve is symmetric. Its optimum is therefore identical to its mean. Also, its tolerance is almost identical to its standard deviation when the maximum of the curve is small (Ter Braak \& Looman, 1986). The range of occurrence of a species is largely restricted to an interval of length $4 t$ (Fig. 2).

The idea behind the maximum likelihood method is to fit Gaussian logit curves to the releve data. This is done by varying the parameter values of the model in order to maximize the

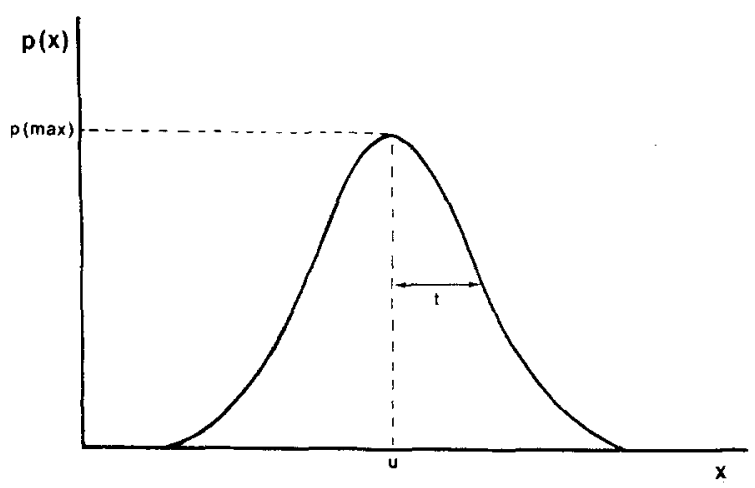

Fig. 2. Gaussian-logit response curve $(p(x)=$ probability of occurrence of the species at value $x, p(\max )=$ maximum probability of occurrence, $x=$ environmental variable, $t=$ tolerance, $u$ = optimum).

likelihood. The likelihood of a set of parameter values is defined as the probability of collecting the same data when this set of values were the true set of parameter values. In the present case the likelihood is taken to be the product of $p^{y}(1-p)^{1-y}$ over all relevés and species, with $p=p_{i k}$ and $y=1$ or 0 depending on whether species $k$ is present or absent in relevé $i$. Logistic regression as utilized by Ter Braak \& Looman (1986) is a special case of the maximum likelihood method, in which the species parameters $\left(u_{k}, t_{k}\right.$ and $\left.c_{k}\right)$ are estimated from data on species occurrence and known values of $x_{i}$. We could apply logistic regression here, using the moisture values from the weighted averaging method. However, in estimating the tolerances of the species it is more natural to assume, as in equation (1), that the optima are known, namely, that they are equal to Ellenberg's indicator values. From this assumption maximum likelihood estimates are derived for the moisture values of the releves as wel as for the tolerances and maxima of the species. The maximum likelihood estimates are obtained with an iterative algorithm:

(1) Start with the moisture values obtained by weighted averaging.

(2) Estimate the tolerance and maximum of each species from that species' data and the current moisture values.

(3) Estimate a new moisture value for each releve from the floristic data, the species' optima and the current values for the tolerances and maxima of the species.

(4) Check whether the moisture values have changed, and if so, go back to step (2), otherwise stop.

In step (2) and step (3) the likelihood is maximized for each species and each relevé separately and, as a result, the total likelihood increases with each step. Step (2) resembles a Gaussian logit regression, but differs in that the optimum is given instead of being estimated. Step (3) of the maximum likelihood procedure has the attractive property that species with a small tolerance will have a greater effect on the estimation of the moisture value of a relevé than species with a large tolerance (cf. Ter Braak \& Barendregt, 1986).

With the maximum likelihood method one can test statistically whether a species' optimum as specified by Ellenberg's indicator value is consistent with the indicator values of the other species. In this test the likelihood calculated above is compared with 
a likelihood that is maximized also with respect to the value of the species' optimum (cf. Ter Braak \& Looman, 1986). When the difference in residual deviance $(=-2 \log$-likelihood) is larger than the critical value of a chi-square distribution with 1 degree of freedom, the species' optimum is shown to differ significantly from the value specified by Ellenberg (1979) and is therefore inconsistent with the indicator values of the other species. In principle this test can be carried out for each species in turn. Howev$\mathrm{er}$, in the present case, the test is very laborious because of the large number of parameters in the model. Because it is unlikely that the moisture values of the relevés will change much, when the second likelihood is maximized, they may just as well be kept fixed. Then, the statistical test amounts to comparing a species' indicator value with its optimum as estimated by a Gaussian logit regression of the data of this particular species on fixed moisture values. Instead of testing by deviance, we checked whether Ellenberg's indicator value lay within the $95 \%$-confidence interval for the optimum. The construction of this interval is described by Ter Braak \& Looman (1986). Such intervals were only constructed for species occurring in more than five relevés.

\section{Data}

In this study, 1041 relevés (all from 1980-1982) were used representing the vegetation of the diluvial area in the western part of the province of Noord-Brabant, The Netherlands (Gremmen et al., 1985) as follows: 323 relevés of woodland, 312 grassland, 250 marsh and ditch vegetation, 94 heathland and bog, and 62 other types. Quadrat size ranged from $4 \mathrm{~m}^{2}$ in bog and grassland to $200 \mathrm{~m}^{2}$ in woodlands.

Trees, large shrubs, and species that occurred less than 3 times were excluded. A total of 311 species remained, on average 13 per relevé; 280 of them had been assigned indicator values for moisture (Ellenberg, 1979). Most species have indicator values that are in the middle range $(5-9)$. Of the species with more extreme moisture values $12 \%$ have an indicator value of 4 or less, and $16 \%$ have one above 9 .

\section{Results}

The moisture values of the releves estimated by the weighted averaging method showed a markedly uneven distribution, with many more 'wet' than 'dry' relevés (Table 2 ). These moisture values were strongly correlated $(r=0.94)$ with those estimated by the maximum likelihood method, but as shown in Table 2, the estimated values for any single relevé may differ considerably $(30 \%$ of the relevés differed by more than 0.5 unit, and $9 \%$ of the relevés by more than 1 unit).
Table 2. Comparison of the estimates of the moisture values of the relevés resulting from the weighted averaging method $\left(x_{\mathrm{WA}}\right)$ and the maximum likelihood method $\left(x_{\mathrm{ML}}\right)$. Entries refer to number of relevés.

\begin{tabular}{|c|c|c|c|c|c|c|c|c|c|c|}
\hline $\begin{array}{l}\mathrm{x}_{\mathrm{WA}} \\
\mathrm{x}_{\mathrm{ML}}\end{array}$ & 123 & 4 & 5 & 6 & 7 & 8 & 9 & 10 & 1112 & Total \\
\hline 1 & & 1 & & & & & & & & 1 \\
\hline 2 & & & 3 & & & & & & & 3 \\
\hline 3 & 1 & 11 & 5 & 2 & & & & & & 19 \\
\hline 4 & & 1 & 13 & 1 & & & & & & 15 \\
\hline 5 & & 1 & 67 & 36 & 1 & & & & & 105 \\
\hline 6 & & & 28 & 220 & 61 & & & & & 309 \\
\hline 7 & & & & 15 & 122 & 13 & & & & 150 \\
\hline 8 & & & & & 43 & 99 & 6 & & & 148 \\
\hline 9 & & & & & 16 & 108 & 76 & 4 & & 204 \\
\hline 10 & & & & & & 3 & 24 & 10 & & 37 \\
\hline 11 & & & & & & & 7 & 19 & 111 & 38 \\
\hline 12 & & & & & & & & & 102 & 12 \\
\hline
\end{tabular}

$\begin{array}{llllllllllllll}\text { Total } & 0 & 0 & 1 & 14 & 116 & 274 & 243 & 223 & 133 & 33 & 21 & 3 & 1041\end{array}$

Table 3. Comparison of the estimates of the species amplitudes from the weighted averaging method (SD, Equation (1)) and the maximum likelihood method ( $t$, Equation (2)). Entries refer to number of species.

\begin{tabular}{lllllllllr}
\hline SD & 0.0 & 0.5 & 1.0 & 1.5 & 2.0 & 2.5 & 3.0 & & Total \\
& & - & - & - & - & - & - & - & \\
\\
& 0.5 & 1.0 & 1.5 & 2.0 & 2.5 & 3.0 & 3.5 & $\geq 3.5$ & \\
\hline $0.0-0.5$ & 6 & 30 & 1 & & & & & & 37 \\
$0.5-1.0$ & & 30 & 20 & 1 & & & & & 51 \\
$1.0-1.5$ & & 18 & 51 & 7 & 4 & & & & 80 \\
$1.5-2.0$ & & 1 & 32 & 27 & 2 & & & & 62 \\
$2.0-2.5$ & & & 7 & 13 & 4 & 1 & & & 25 \\
$2.5-3.0$ & & & 2 & 3 & & 2 & & & 7 \\
$3.0-3.5$ & & & 1 & 2 & 2 & & & & 5 \\
$\geq 3.5$ & & 1 & 1 & 5 & 1 & 1 & 1 & 3 & 13 \\
Total & 6 & 80 & 115 & 58 & 13 & 4 & 1 & 3 & 280 \\
\hline
\end{tabular}

The simplistic estimate of a species' amplitude, that is the sample standard deviation $(S D)$ of the moisture values of the relevés in which the species occurs, showed low correlation (0.2) with the more subtle estimate of $S D$ by equation (1), which was on average 1.3 moisture scale unit. The maximum likelihood method tended to result in somewhat larger estimates of the amplitude than $S D(\mathrm{Ta}-$ ble 3). Species with indicator values of 11 and 12 had on average a markedly smaller tolerance than other species. This may be so because they are water plants. 
In general the maximum probability of occurrence of a species estimated by the maximum likelihood method, was quite small; for only $23(8 \%)$ of the species the maximum exceeded 0.50 and for 154 $(55 \%)$ it was less than 0.10 . Thus, the occurrence of most species cannot be predicted with confidence from the moisture value of the site alone.

Figure 3 shows some typical examples of the response histograms and Gaussian logit curves fitted by the maximum likelihood method and by Gaussian logit regression.
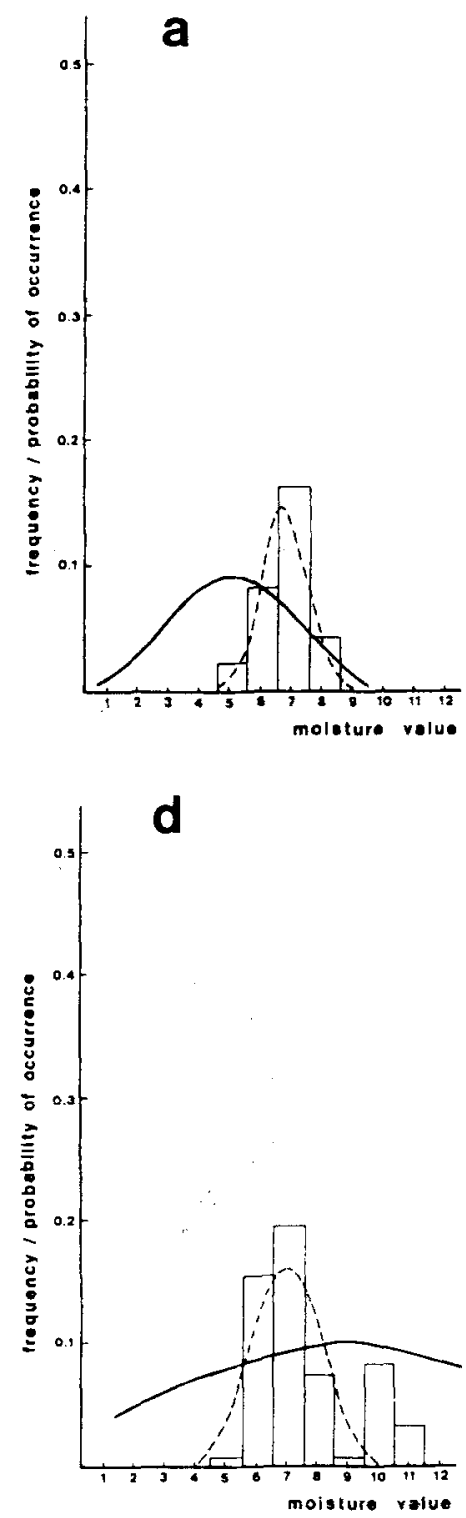
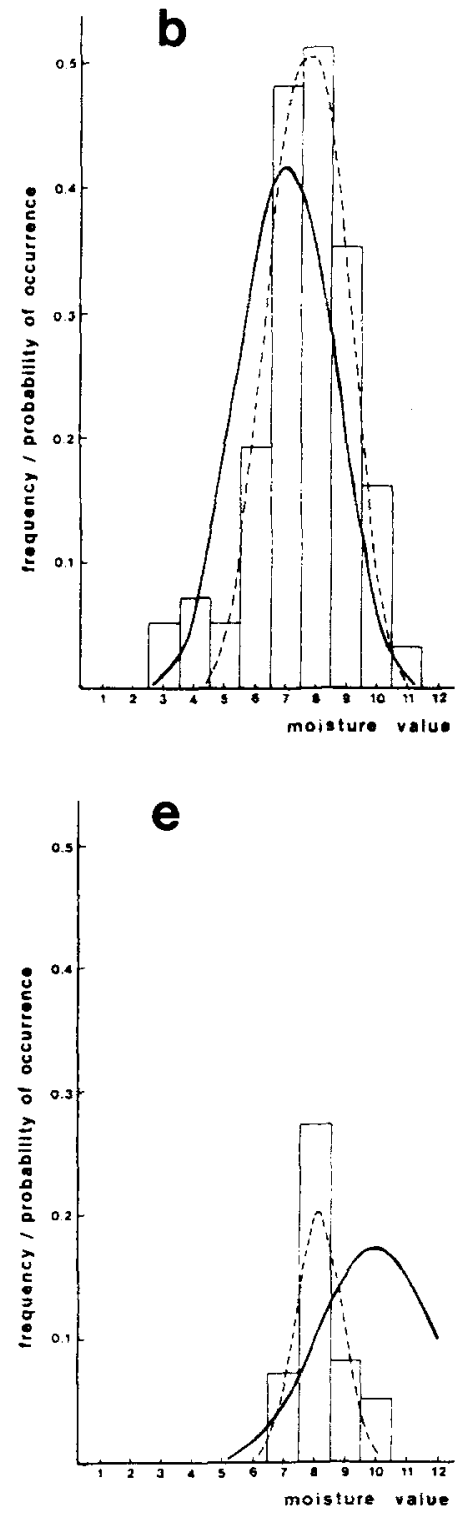
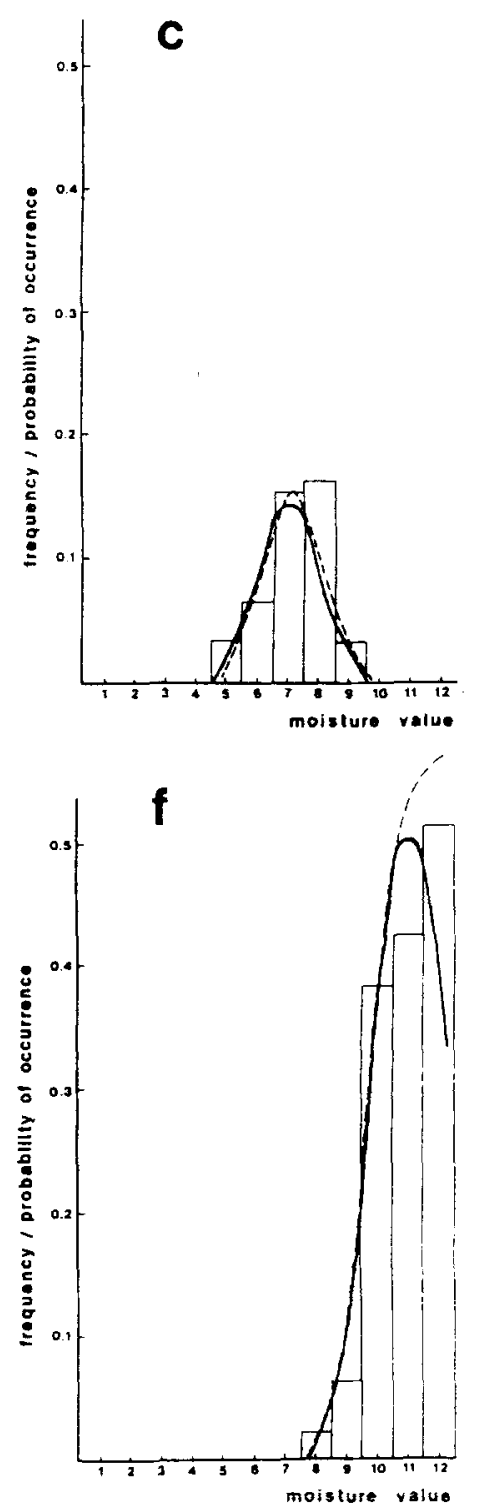

Fig. 3. Some examples of response histograms (bars) and estimated response curves. $(-$ = response curve estimated by the maximum likelihood method; $---=$ response curve estimated by Gaussian logit regression). $F=$ Ellenberg moisture value, $t=$ tolerance $/$ estimated by the maximum likelihood method, $S D=$ ecological amplitude estimated by the weighted averaging method. (a) Heracleum sphondylium $F=5 ; t=2.1 ; S D=1.7$ (b) Juncus effusus $F=7 ; t=1.4 ; S D=1.4$ (c) Juncus subuliflorus $F=7 ; t=1.0 ; S D=0.9$ (d) Alopecurus geniculatus $F=9 ; t=5.5 ; S D=2.2$ (e) Iris pseudacorus $F=10 ; t=1.8 ; S D=1.8$ (f) Lemna minor $F=11 ; t=1.0$; $S D=1.0$. 
In some cases the mean of the response histogram deviates strongly from the indicator value of the species (Fig. 3a, e). In those cases the curve fitted by maximum likelihood with the species' indicator value taken as a fixed optimum, also deviates strongly from both the response histogram and the curve fitted by Gaussian logit regression. By using Gaussian logit regression 95\%-confidence intervals for the optimum could be constructed for $175(=73 \%)$ of the 240 species occurring in more than five relevés. For $45(=26 \%)$ of these, Ellenberg's (1979) indicator value for moisture lay more than 0.5 unit outside this confidence interval. The extra 0.5 unit was used to allow for the fact that Ellenberg (1979) reports whole numbers. Thus for instance, an indicator value of 6.45 would be reported as 6 . The indicator values of these species therefore are inconsistent with those of the other species. Table 4A gives information on species with an extreme deviation $(\geq 1.7)$ between the Ellenberg moisture value and the estimated optimum. When no $95 \%$-confidence interval could be calculated, the relationship between moisture and probability of occurrence was either non-significant (21 species) or sigmoid rather than unimodal (44 species), as judged by the deviance test at the 5\%-level (cf. Ter Braak \& Looman, 1986). No great inconsistencies in indicator value could be shown for species with a sigmoid relationship, because those with an Ellenberg indicator value of less than 7, showed a decreasing fitted response curve and those with an indicator value of 7 or more showed an increasing response curve (cf. Fig. 3f). It should be noted that a nonsignificant relationship or optimum may be due to a low frequency of a species in our data set and does not necessarily point to inconsistencies in Ellenberg's indicator values.

Gaussian logit regression was also used to check whether species Ellenberg (1979) considered indifferent, were also indifferent in our data set. For 28 of the 38 such species that occurred in 6 or more relevés, a $95 \%$-confidence interval for the optimum could be calculated, and for 14 species the estimated tolerance was even less than 1.0 unit. Table 4B lists the species with the narrowest ecological amplitude $(t<0.9)$.

Our data set contained only three herbaceous species not mentioned by Ellenberg (1979) that occurred in more than 5 relevés; their indicator values were estimated by Gaussian logit regression (Table 4C).
Table 4. Ellenberg moisture value $(F)$, estimated optimum, $95 \%$-confidence interval for the optimum and estimated amplitude (tolerance) of a number of species. A. Species with a large discrepancy between Ellenberg moisture value and estimated optimum. B. Species with a narrow ecological amplitude, although regarded as indifferent by Ellenberg. C. Species not mentioned by Ellenberg.

\begin{tabular}{lrlll}
\hline Species name & $F$ & optimum & interval & tolerance \\
\hline A. & & & & \\
Ornithopus perpusillus & 2 & 4.1 & $3.5-4.3$ & 0.5 \\
Stellaria graminea & 4 & 6.0 & $5.0-6.4$ & 1.4 \\
Alopecurus geniculatus & 9 & 6.9 & $6.6-7.1$ & 1.1 \\
Iris pseudacorus & 10 & 8.2 & $8.0-8.4$ & 0.7 \\
& & & & \\
B. & & & & \\
Anemone nemorosa & $\mathrm{x}$ & 6.1 & $6.0-6.3$ & 0.2 \\
Melampyrum pratense & $\mathrm{x}$ & 6.3 & $4.6-7.3$ & 0.5 \\
Bellis perennis & $\mathrm{X}$ & 6.6 & $6.3-6.8$ & 0.6 \\
Prunella vulgaris & $\mathrm{X}$ & 7.1 & $6.8-7.5$ & 0.6 \\
Ranunculus acris & $\mathrm{x}$ & 6.9 & $6.7-7.0$ & 0.7 \\
Capsella bursa-pastoris & $\mathrm{x}$ & 4.6 & $3.5-5.0$ & 0.8 \\
& & & & \\
C. & & & & \\
Eleocharis multicaulis & $?$ & 9.1 & $9.0-9.3$ & 0.3 \\
Epilobium obscurum & $?$ & 7.0 & $6.9-7.3$ & 0.6 \\
Myosotis laxa & $?$ & 7.8 & $7.5-8.1$ & 0.7 \\
\hline
\end{tabular}

\section{Discussion}

\section{The ordinal scale of Ellenberg's indicator values}

Ellenberg's indicator values are ordinal (strictly speaking values 11 and 12 are nominal); from the values in Table 1 we may infer which of two species prefers wetter conditions, but not the magnitude of the difference. But, in the methods applied here, the indicator values are treated as if they were quantitative, that is, as if they were measured on an interval scale. Durwen (1982) raised objections against such a quantitative treatment. In our opinion the ordinal nature of Ellenberg's moisture scale is far less important than the shape of the response curves, which should be symmetric (cf. Ter Braak \& Barendregt, 1986). In the maximum likelihood method, a particular symmetric response curve was assumed - although response curves that are monotone by truncation, could also be dealt with. This condition of symmetry is equally important in the weighted averaging method, as mean and standard deviation are only useful characteristics for response curves that are more or less symmetric. After inspecting the response histograms of all species (cf. Fig. 3) we 
concluded that the assumption of symmetry was not unreasonable, except, of course, for species with extreme optima. Therefore, we used the moisture indicator values of Ellenberg without transformation.

\section{Comparison of the two methods}

The weighted averaging method has three major problems. Firstly, as the number of relevés in each moisture class is not equal (Table 2), the estimates of the probability of occurrence in a class are not equally precise for all classes. The estimate of $S D$ in equation (1) is closely related to the $S D$ of the response histogram (Fig. 1), and it would seem reasonable to give less weight to classes with relatively few relevés. However, any such weighting policy, would make the estimator for $S D$ again dependent on the distribution of the relevés, and thus cause bias.

A second problem is caused by relevés of extremely wet or extremely dry sites. The moisture values of these relevés will always be too low and too high, respectively, because only a few species indicate extreme conditions and many more species indicate conditions that are less extreme. Just by their numbers the probability of species of the latter group occurring at extreme sites is higher than of species indicating extreme conditions. This results in a general trend towards more moderate moisture values for extreme relevés, and this also results in a bias in the estimates for $S D$. Thirdly, the response histograms of species with an extreme indicator value will be truncated (cf. Fig. $3 \mathrm{f}$ ) and it is not clear how the $S D$ value of such species should be interpreted. The problem is partly one of definition, that is, when the response curve is truncated because more extreme conditions do not exist, it is not clear how $S D$ should be defined, and partly one of estimation, namely when the response curve is truncated because more extreme conditions were not sampled, it is not clear how $S D$ should be estimated. We do not know how to solve this problem in the weighted averaging method.

In the maximum likelihood method a specific model has to be adopted, in our case the Gaussian logit model. This is a disadvantage, since we do not really know the correct model. When the model is correct, the resulting estimates are better than in the weighted averaging method, but when it is incorrect, the meaning and quality of the estimates are unknown. We investigated the goodness-of-fit of the Gaussian logit curves obtained from the regressions with the usual chi-square test on the basis of observed and expected numbers of presence and absence in the 12 moisture classes. At the 5\% level 72 species $(=27 \%$ ) showed significant lack-offit. An example is Alopecurus geniculatus (Fig. 3d). The response histogram suggests gross deviations from the Gaussian logit curve in moisture classes 10 and 11 , but these are due to only four occurrences. The important deviation is the low frequency of occurrence in moisture class 9. Despite the deviations, we believe that for our purpose and data the Gaussian logit model is a good compromise between model complexity and goodnessof-fit.

The problems in the weighted averaging method are largely solved automatically in the maximum likelihood method, where a truncated response curve is assumed to be part of a full Gaussian logit curve. However, an unexpected new problem arose, namely that the distribution of the moisture values of the relevés showed local minima near integer values.

This artifact (which is not apparent in Table 2) is because the Ellenberg (1979) indicator values are all integer values and in our method form the optima of the species' response curves. The maximum likelihood estimate of the moisture value of a releve is based both on the species present and the species absent. When a species is present, it forces the estimate in the direction of the species' indicator value, whereas, when a species is absent, it forces the estimate away from the species' indicator value. $\mathrm{Ab}$ sence of a species usually has far less influence than presence, that is, when the maximum probability of occurrence of the species is low (Ter Braak \& Barendregt, 1986). But the number of species absent in a relevé is large compared to the number of species present. If, for instance, the true moisture value of a relevé is 6.0 , all species with an indicator value of 6 that are absent will force the estimate away from the value 6.0 and this force cannot be counteracted by the presence of a small number of species with this same indicator value. The maximum likelihood estimate thus tends to avoid the integer values. We believe that in the present study this artifact is not a very serious problem. Because the average width of the response curves is large as compared to the scale of these irregularities, the fitting of curves will still give a reasonable estimate of the species tolerance.

The maximum likelihood method has the additional advantage over the weighted averaging method by giving approximate standard errors of estimates, which makes it possible to test the internal consistency of the Ellenberg indicator values. 


\section{Improving the indicator values by ordination?}

Clausman (1980) attempted to improve indicator values by an iterative procedure; he calculated moisture values for the relevés from the indicator values and then new indicator values from the moisture values, and then new moisture values from the new indicator values, and so on. This procedure is essentially an ordination method. For example, when weighted averaging is used in each calculation, the method amounts to reciprocal averaging. By consequence, the original meaning of the indicator values may get lost.

We applied detrended correspondence analysis (Hill \& Gauch, 1980), to our data and found practically no correlation between the (initial) moisture values of the relevés and the (final) scores on the first axis $(r=0.01)$. The first axis turned out to be highly correlated $(r=0.99)$ with the nitrogen values of the relevés, estimated by averaging the Ellenberg indicator values for $\mathrm{N}$, whereas the second axis was highly correlated $(r=0.99)$ with the moisture values. Applied to our data, Clausman's (1980) method would have changed the Ellenberg's indicator values for moisture into indicator values for nitrogen, which is clearly unwanted! Consequently, ordination cannot be used to improve indicator values, except in the hypothetical case that it is certain that the main variation in the species data corresponds exactly to the factor one wants to improve the indicator values of. Therefore, we kept the indicator values fixed in both our methods and tested each species separately to see if its value was consistent with the indicator values of the other species.

Due to the implicit nature of Ellenberg's definition of moisture, it is impossible to improve the moisture values in a statistically sound way on the basis of floristic data only.

\section{On generalizing the results}

Our results show the ecological amplitude $(S D$ or tolerance) of a species to be about 1.0 to 1.5 units "on Ellenberg's moisture scale. Consequently, the range of a species' occurrence is estimated to be on average 4-6 units. It is difficult to say how these results are affected by conditions specific to our study area. The detrended correspondence analysis showed nitrogen to be the environmental variable that is most important for explaining the floristic variation in our data. Consequently, the assumption in the maximum likelihood method of independence of the species is incorrect. Fortunately, nitrogen was practically uncorrelated with moisture, and therefore unlikely to have distorted the results to a large extent. The fact that moisture is shown to be the second most important environmental variable in our data set also gives some confidence in the results. In different geographical regions, the environmental variables that are most important for explaining the species distribution may differ. Especially when these factors are correlated with moisture, the estimates of the amplitude of a species with respect to moisture may differ because of distortion by these factors. In principle, the problem of other influential variables can be overcome in the maximum likelihood method by analysing more than one variable simultaneously. We may attempt this in the future.

\section{Conclusion}

The use of Ellenberg's moisture values on floristic data in estimating site moisture is an example of environmental calibration. Ellenberg's method of environmental calibration assumes a simple model of the responses of plant species to moisture: symmetric, unimodal response curves and equal amplitudes. This model does not include interaction effects of other environmental variables with moisture. A more precise calibration system necessarily has to include such interactions. Such a system could be derived from actual measurements of environmental variables and associated floristic data (Ter Braak \& Barendregt, 1986), but would lose the simplicity and supposed general applicability of the Ellenberg system. May our results serve to increase the confidence with which Ellenberg's indicator values for moisture are used.

\section{References}

Böcker, R., Kowarik, I. \& Bornkamm, R., 1983. Untersuchungen zur Anwendung der Zeigerwerte nach Ellenberg. Verh. Ges. Ökol. 9: 35-56.

Clausman, P. H. M. A., 1980. Ecologische interpretatie van vegetatieopnamen m.b.v. een computer. WLO-Meded. 7: 92-98. 
Durwen, K.-J., 1982. Zur Nutzung von Zeigerwerten und artspezifischen Merkmalen der Gefäszpflanzen Mitteleuropas für Zwecke der Landschaftsökologie und -planung mit Hilfe der EDV-Voraussetzungen, Instrumentarien, Methoden und Möglichkeiten. Arbeitsber. Lehrst. Landschaftsökol. Münster 5: $1-138$.

Ellenberg, H., 1979. Zeigerwerte der Gefäszpflanzen Mitteleuropas. 2nd ed., Scripta Geobotanica 9, Göttingen.

Ellenberg, H., 1983. Vegetation Mitteleuropas mit den Alpen in ökologischer Sicht. 3rd ed., Ulmer Verlag, Stuttgart.

Gremmen, N. J. M., Reijnen, M. J. S. M., Wiertz, J. \& Van Wirdum, G., 1985. Modelling for the effects of ground-water withdrawal on the species composition of the vegetation in the Pleistocene areas of The Netherlands. In: Ann. Rep. 1984. Research Institute for Nature Management, Arnhem, pp 89-111.

Hill, M. O. \& Gauch, H. G., 1980. Detrended correspondence analysis: an improved ordination technique. Vegetatio 42 : 47-58.
Persson, S., 1981. Ecological indicator values as an aid in the interpretation of ordination diagrams. J. Ecol. 69: 71-84.

Reijnen, M. J. S. M. \& Wiertz, J., 1984. Grondwater en vegetatie: een nieuw systeem voor kartering en effectvoorspelling. (Engl. Summary) Landschap 1: $261-281$.

Smeets, P. J. A. M., Werger, M. J. A. \& Tevonderen, H. A. J., 1980. Vegetation changes in a moist grassland under altered water conditions. Biol. Conserv. 18: 123-142.

Ter Braak, C. J. F. \& Barendregt, L. G., 1986. Weighted averaging of species indicator values: its efficiency in environmental calibration. Math. Biosci. 78: 57-72.

Ter Braak, C. J. F. \& Looman, C. W. M., 1986. Weighted averaging, logistic regression and the Gaussian response model. Vegetatio 65: 3-11.

Whittaker, R. H., 1956. Vegetation of the Great Smoky Mountains. Ecol. Monogr. 26: 1-80.

Accepted 20.8.1986. 